\title{
"El poderoso que habla": el río y las dinámicas socioculturales en la poesía de José María Arguedas
}

\author{
Mauro Mamani Macedo \\ Universidad Nacional Mayor de San Marcos \\ mmamanim@hotmail.com
}

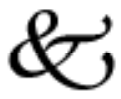

\begin{abstract}
Resumen
El objetivo de este artículo es observar cómo el río establece una poética del movimiento, y cómo esta dinámica trasciende diversos ámbitos. Esta transferencia de un ser a otro configura un mecanismo que no opaca el ser, sino que afirma y potencia su identidad, estableciéndose un fluir de identidades. Para la explicación seguiremos el análisis crítico del discurso. Este abre la posibilidad de tomar categorías de diferentes disciplinas como la antropología, la sociología, la linguística y la literatura. Esta múltiple y dialogante visión posibilitará observar el objeto en toda su complejidad. Por ejemplo, explicar cómo las propiedades del río: fuerza, sonido, música, energía, avance son transferidos a los hombres, a los animales y a las colectividades. También establecer las diversas dinámicas y funciones que desempeña el río en la escritura de Arguedas. Este estudio se centra en la poesía donde la figura del río asume dimensiones divinas: hablar con los dioses mayores o dimensiones humanas, llorar cuando las condiciones de los hombres son adversas.
\end{abstract}

Palabras claves: Poesía, quechua, literatura, identidad, movilidad.

\begin{abstract}
The objective of this study is to observe how the river provides a poetic movement, and how this dynamic transcends various fields. This transfer from one individual to another set up a mechanism not being opaque, but affirms their identity and power, establishing a flow of identities. For an explanation will follow the critical discourse analysis. This analysis provides the possibility of taking categories from different disciplines such as anthropology, sociology, linguistics and literature. This manifold
\end{abstract}


vision will make possible to observe the object in all their complexity. For example, explain how the properties of the river like force, sound, music, energy, progress are transferred to men, animals and communities. Also set the various dynamics and functions played by the river in the writing of Arguedas. This study focuses on the poetry of the river where the figure assumes divine dimensions: talk to the elder gods or human dimensions, to cry when the conditions of the men are adverse.

Keywords: Poetry, Quechua, Literature, Identity, Mobility.

\section{Los múltiples ramales del río}

La vasta obra de Arguedas está surcada por múltiples ríos divinizados o humanizados. Ellos serpentean en el terreno plural de su narrativa, poesía y ensayo. El eco de su voz es simbólico y alcanza espacios distantes, lo que demuestra su gran poder significativo. El río, en su obra, se configura como símbolo cultural, río textual que ha sido absorbido de la naturaleza. Por ello, los ríos son representados en distintas magnitudes en sus diversas funciones.

Uno de los ríos más simbólicos es el Apurímac, al que Arguedas define como "el poderoso que habla", "río sagrado", "Dios que habla". Río difícil de ver, pero fácil de sentir "Porque sólo es posible verlo desde las cumbres, y su voz se oye en todas partes. Corre por el fondo de las quebradas más profundas que es posible imaginar" (1987:151). Esta singularidad de su procedencia y esa capacidad de hacer emerger su voz desde la profundidad hasta los lugares más distantes y altos es lo que le otorga la dimensión divina. Río que puede enturbiar el ánimo o puede limpiar el alma, según la orientación que tome en el ser.

El canto, la fuerza y la voz del río mantienen vínculos con la música. Su energía cósmica es despertada por el canto y se instala en el hombre en forma individual o colectiva.

Una incontenible desesperación despierta este canto, una tristeza que nace de todas las fuerzas del espíritu. Es como un insuperable deseo de luchar y de perderse, como si la noche lóbrega dominada por la voz profunda del río se hubiera apoderado de nuestra consciencia, y se canta sin descanso, cada vez con más ansia y con más angustia. Es un desenfreno de tristeza y coraje. Toda esa esencia del vivir humano agitada con ardiente violencia en todo nuestro mundo interior sensible. (1987:154).

Todo este mundo interno es despertado por el canto. Es como si removiera todos los ríos rebeldes que la habitan porque en un río dormido hay fuerzas que están prontas a avivarse y desatarse de manera incontenible. Por ello, cuando son activadas por el canto surge ese impulso de "luchar y perderse". El río entra en las consciencias, las enardece y las agita con connotaciones ideológicas. Este arranque trasciende la individualidad, por ello, toda la vida humana 
se ve agitada por la fuerza del canto; un canto que se sustenta en la fuerza del río. Canto y río, música y río, río y rebeldía permiten la transferencia de sus propiedades a los hombres. El canto y la voz del río son de otra naturaleza. Es como una energía cósmica, armoniosa, seductora que estalla en el corazón de los hombres, pero este estallido no despedaza u oscurece el corazón, por el contrario, arde y quema. Esto desenlaza la danza y la guerra. Es la esencia espiritual que impulsa el ansia y la angustia, que estimula la acción y la vida.

En las hondas quebradas, en las piedras y en el agua en movimiento estalla la música en coordenadas que expresan la belleza del canto del río. Estos son sus instrumentos “... y de grandes ríos que cantan con la música más hermosa al chocar contra las piedras y las islas”. Debido a esto, el verbo chocar aquí no significa golpear y destruir, sino tocar en el sentido musical. Aquí los acordes están entre las piedras y las islas. Ellas colaboran en la construcción del sonido. Estas dos instancias, piedra e isla, por su nivel denotativo, anulan toda comunicación: la piedra cerrada a la comunicación y la isla alejada de todo diálogo. Sin embargo, en la función que representa Arguedas, las islas y las piedras se comunican con el mundo, ayudan a configurar las armonías. No son, en el sentido empobrecido, objetos inertes y que están allí para ser golpeadas por las aguas, sino que están para corresponder a las aguas, a los ríos; así juntos entonan la música de los ríos. Entonces, no hay quietud sino movimiento; no se neutraliza el diálogo, sino que se estable porque las piedras están animadas; las islas, conectadas; lo fijo y quieto es ganado por lo dinámico; hay diálogo y movimiento, cooperación en el momento del concierto musical. Este río también puede celebrar los avances y las victorias cuando sus hijos han triunfando "Está cantando el río" (1984:11). Es ese dios que celebra junto a los hombres sus avances sobre la ciudad. Por ejemplo, la llegada de los indios a Lima, tal como el enunciador lo describe. La alegría del río es la alegría de los hombres.

El río es un elemento simbólico en la cosmovisión andina. Allí se le respeta porque es capaz de transferir destrezas, crear música nueva para impartirla a los hombres, como los arpistas que tienen sus pak'chas. Es el río quien les otorga toda la musicalidad de sus aguas; de allí nace la música clara y poderosa, original como la música de los Arpistas en la novela Diamantes y Pedernales.

La noche del 23 de junio esos arpistas descendían por el cauce de los riachuelos que caen en torrentes al río profundo, al río principal que lleva su caudal a la costa. Allí, bajo las grandes cataratas que sobre roca negra forman los torrentes, los arpistas "oían". iSólo esa noche el agua crea melodías nuevas al caer sobre la roca y rodando en su lustroso cauce! Cada maestro arpista tiene su pak'cha secreta. Se echa, de pecho, escondido bajo los penachos de las sacuaras; algunos se cuelgan de los troncos de molle, sobre el abismo en que el torrente se precipita y llora. Al día siguiente, y durante toda la fiesta del año, cada arpista toca 
melodías nunca oídas. Directamente al corazón, el río les dicta música nueva (1983:19) ${ }^{1}$.

Es el río quien administra su magisterio, quien pone la música en el corazón de los hombres, quien ordena y da la secuencia de sus sonidos, la distribución de sus acentos y de sus cadencias. Es quien emite el primer canto; este luego es reproducido por todas la regiones, entonces no es un canto para uno sino para el pueblo, por ello los arpistas elegidos son sus intermediarios.

Este río, con los mismos valores que se practican en la vida del pueblo indio, es representado en la obra narrativa y poética de Arguedas; además, es estudiado en sus ensayos. Un ejemplo de ellos, es su magnífico artículo "El carnaval de Tambobamba" donde el río tiene un marcado protagonismo, con claras alusiones a las confrontaciones sociales. Por esta razón, explica Usandizaga, el río dormido como una piedra guarda una energía contenida, energía sagrada y terrible que trae destrucción, pero también limpieza ${ }^{2}$ y, sobre todo, resurrecciones. Todo ello se cifra en la manifestación del despertar de las fuerzas dormidas en la piedra y en los ríos (2006: 230). El río muestra una fuerza de movilidad. Esta es trasladada al campo humano para que pueda afirmar su identidad en tanto fluir, esto encaja con la forma de pensar andina donde la identidad siempre es relacional. Identidad que se construye en función a los otros, esos otros no son solo los semejantes, sino los otros hermanos como las plantas y los animales. En este universo de la naturaleza, vivo (kawsay) el río entra en diálogo tenso con el hombre para que surja la identidad y la música. Pero también, un río puede ser calificado como un toro por su bramido o el correr de un toro puede ser calificado con las correntadas, crecidas o repuntes de lo ríos. Por esta razón, no hay identidades fijas y cerradas, sino abiertas y dinámicas. Este símbolo puede mostrarse con una movilidad diversa, puede instalarse en los animales como el toro, el caballo o la culebra que tienen el mismo desplazamiento horizontal, de atrás hacia adelante, mostrando un avance. De allí traslada la figura en movimiento a los bailes, a las danzas guerreras y se proyecta a las grandes marchas andinas que buscan justicia social.

También el río está asociado a la candela, la cual tiene dos movimientos. Uno vertical en tanto crece en altura porque se enardece y se eleva. El otro movimiento es horizontal. Este se observa cuando el fuego avanza a ras del suelo quemando las plantas. Allí se pone en práctica los procesos de nutrición de la tierra, tal como ocurre cuando se queman los pastos secos. Esta ceniza, que resulta de la quema, nutre la tierra para que las plantas broten con rebeldía.

1 En esta novela el Upa Mariano también es un arpista que toca dulce, pero se insinúa que el aprendizaje viene de los animales "-Porque pasa el día con los pájaros cantores será que así dulce toca- decían los viejos y las mujeres”. Diamantes y pedernales. p. 16.

2 Muy similar al fuego que quema la paja, generando limpieza para el brote de la hierba. 
También el río está vinculado al rayo, ya que este tiene un movimiento intenso como el de una culebra aérea. Esta intensidad se instala en el corazón de los hombres, pero también puede ser visto en los ámbitos sociales cuando se desatan las luchas de reivindicación social. La figura del río no es una sustancia fija sino que se expande, difunde su potencia. Temblor y agitación pueden ingresar en la vena de la gente. De este modo, la sangre arde y el espíritu se subleva, por ello, la gente es guerrera.

La imagen del río puede tomar distintas formas: huaycos, venas enardecidas, sangre que grita. Pero también puede estar representada como animales. Por ejemplo, un río es como un toro, por ello, que se señala que brama y corre como los toros en desatada carrera. También puede ser como serpiente, como el amaru, por ejemplo como en los grandes movimientos comunales.

De todo ello, se desprende las múltiples relaciones del río: culebra/amaru, fuego, viento, rayo, toro, caballo, aire, candela, camino, movimientos sociales como la protesta, donde se representa como un río de gente que corre entre los caminos, calles como cauces por donde se desplaza el río de gente que marca el avance de las personas; esto es visto como el repunte de las aguas convulsas de los ríos, tal como se describe en Los ríos profundos. En todos ellos, se presenta ese desplazamiento sinuoso de caminar, fuerza que impulsa, que quema, que destruye, pero también esconde la idea de renovación.

El río también es visto como grito insuperable que alcanza espacios desconocidos y alturas admirables, entonces sirve para calificar la fuerza del grito doloroso cuando se ejecuta con la intensión de denuncia. Un grito profundo y tremendo. Esto lo observamos en el poema "Qué Guayasamin" cuando expresa la inmensa necesidad de pintar el grito del dolor. "Tú, ardiente hermano/ grita todo esto/ con voz aún más poderosa/ e incontenible que el Apurímac" (1984: 25). Es un dios que habla y su voz tiene dos características. Es poderosa, Arguedas lo traduce como "el poderoso que habla" lo que califica lo enérgico y vigoroso, pero también, da cuenta de su divinidad y su poder incontenible, ya que su avance es imperturbable, avance sin descanso como el trabajo de la comunidad andina, como las grandes luchas comunales. Esta es la intensión de este poema donde se pinta el extremado dolor del hombre, por ello, su pintura grita y es tan alto como la voz del Apurímac, es más, es un grito que supera la voz del Dios que habla.

Esta intensidad de la voz también es representada cuando el yo poético menciona que quiere intensificar la fuerza de su voz. Esto se observa cuando se dirige a su dios, en actitud implorativa "iSomos todavía! Voceando tu nombre, como los ríos crecientes y el fuego que devora la paja madura...”. (1984:13). Esta voz intensa es la que se necesita para llegar a los lugares donde se ubican los dioses mayores, solo con la voz divina del río es posible llegar a ellos, informarles, agradecerles o pedirles que los acompañe en sus desplazamientos. 
El río también es símbolo del secreto y la comunicación “¿Qué hay a la orilla de esos ríos que tú no conoces, doctor?”(1984:43). Es el límite y la frontera de lo conocido y lo no conocido; es el espacio que oculta, pero que también acerca, convoca. Es una frontera y un paso. Esto para configurar la existencia de dos bandas. De un lado, un mundo costeño que desconoce la profundidad y la altura de los andes y de la otra banda, los indios con sus andenes y sus cultivos. Pasar el río es encontrarse y comunicarse; es compartir y vivir como hermanos, tal como lo plantea Arguedas en su utopía posible.

También está asociado al caminar de un toro, a ese movimiento que hace temblar la tierra "nuestro río sagrado está bramando" (1984: 11). Arguedas utilizará el bronco sonido que hace el toro cuando camina para calificar la voz del río. "¿De qué están hechos mis sesos? ¿De qué está hecha la carne de mi corazón” . Los ríos corren bramando en la profundidad...” (1984:43). La fuerza del un toro al correr, que hace temblar la tierra, es usada para calificar la fuerza de las aguas que también hacen temblar a la tierra, y el bramido del toro es la voz pesada de los ríos. También puede ser comparado con el caballo. "iHermoso caballo de crin brillante, indetenible y permanente, que marcha por el más profundo camino terrestre!" (1983:61), muestra la imperturbable y majestuosa marcha del caballo para calificar el movimiento del río.

El río puede trasladar su poderosa vitalidad al hombre. "iEstamos vivos; todavía somos! Del movimiento de los ríos y la piedras, de las danza de los árboles y montañas, de su movimiento, bebemos sangre poderosa, cada vez más fuerte" (1984:13). El movimiento singular del río hace que se reanime y se cargue de fuerza, hace que ese indetenible fluir de sus aguas se convierta en el fluir indetenible de la vida del hombre.

En el orden divino hay jerarquías, el Apurímac, el río que habla no es superior a todos los dioses. Hay dioses mayores, así cuando el yo poético se eleva por las alturas, como el Hana Pacha, encuentra que su grandeza no es tal, pero le reconoce su poder. "He aquí que los poderosos ríos, los adorados, que partían el mundo, se han convertido en el más delgado hilo que teje la araña" (1984:29). Pero este Dios que habla tiene la capacidad de actuar como intermediario, cuando el yo poético del poema a Túpac Amaru pide a su dios supremo que escuche la palabra del río porque tiene el mensaje de superación. "Padre nuestro, escucha atentamente la voz de nuestros ríos" (1984:13), porque esta voz es la que canta el triunfo de los hombres andinos en la tierra.

Pero también es el dios que se duele con ternura "Escucha sobre el árbol de lambras el canto de la paloma abandonada, nunca amada;/ el llanto dulce de los no caudalosos ríos, de los manantiales que suavemente brotan al mundo". (1984:13), son ríos que saben llorar con un llanto de ternura, que alegran y se duelen como sus hermanos humanos o por ellos; un río humanizado por la emoción. 
El río también puede actuar como una memoria. Esto se puede observar en la novela Diamantes y pedernales, tal como lo explica María Gonzales ${ }^{3}$, se presenta en el pasaje cuando la mujer acobambina mira al río y recuerda a su pueblo. Es como ese fluir del recuerdo, río que incesantemente trae al pueblo en sus aguas; por medio de él se reconecta; es como la corriente viva de la memoria ahora actualizada con la memoria del fluir de los hechos, de lo que no está pero que lo vuelve presente porque lo trae en forma incesante. Pero esta memoria del río no hay que entenderla como una memoria depósito, sino una memoria generadora que se desplaza indetenible sobre el presente y sigue su curso hacia el futuro, arrastrando en sus aguas el pasado o haciendo que el pasado viva en sus aguas en movimiento.

En la escritura de Arguedas, hay la presencia de una poética de la movilización, de la fluidez y de la vitalidad. Connota las aguas en movimiento; estas proyectan la idea de los remezones sociales, cuando la crisis es signada por la fuerza y la intensidad de la reivindicación.

Por ello la presencia del yawar mayu como una categoría. "Los indios llaman "yawar mayu" a los ríos turbios, ya que muestran con el sol un brillo en movimiento, semejante al de la sangre. También llaman "yawar mayu" al momento violento de las danzas guerreras, al momento en el que los bailarines luchan" (1983:14). Estos dos movimientos que están signados por el agua y la sangre implican movimientos de intensidad, de fluidez y de tremenda vitalidad. Además, tienen la misma estructura, así se menciona que los ríos son como las venas de los Apus, esos dioses mayores. El río mismo es un Apu como el Apurímac.

Para Isabelle Tauzin el río "plasma la violencia, la destrucción y el renacimiento" (2008:126). El río tiene la fuerza y la intensidad que es lo que hace devastador su poder. Por ejemplo, cuando "entra el río" es cuando nos hace ver todo su poder. Hay una violencia desatada, una furia, es como si recobrara sus dominios; no hay canal que pueda orientar su camino, hace su camino como él quiere, unas veces recto, otras veces torcido. Pero esta fuerza también es renovadora. El río también está vinculado a los movimientos sociales, como el motín de las chicheras, el que es calificado como un "repunte de agua". Y luego como un "oleaje". Esto se observa en la novela Los ríos profundos. El río asociado al amaru "Fue ya el grito único que se repetía hasta la cola del tumulto. El grito corría como una onda en el cuerpo de una serpiente", que es precisamente el movimiento social. (Unsandizaga 2006, Tauzin 2007). El amaru social.

El río puede devolver nuestro ánimo de vida tal como le ocurre a Ernesto en Los ríos profundos:

3 Cfr. Gonzales, María. Oposiciones y complementariedad en Diamantes y pedernales. Tesis de Licenciatura donde estudia algunos símbolos de José María Arguedas. 2011. 
Yo no sabía si amaba más al puente o al río. Pero ambos despejaban mi alma, la inundaban de fortaleza y de heroicos sueños. Se borran de mi mente todas las imágenes plañideras, las dudas y los malos recuerdos.

Y así, renovado, vuelto a mi ser, regresaba al pueblo; subía la temible cuestas con pasos firmes. Iba conversando mentalmente con mis viejos amigos lejanos: don Maywa, don Demetrio Pumaylly, don Pedro Kokchi... que me criaron, que hicieron de mi corazón semejante al suyo

Durante muchos días después me sentía solo, firmemente aislado. Debía ser como el gran río: cruzar la tierra, cortar las rocas; pasar, indetenible y tranquilo, entre los bosques y montañas; y entrar al mar, acompañado por un gran pueblo de aves que cantarían desde la altura.

Durante esos días los amigos pequeños no me eran necesarios. La decisión de marchar invenciblemente, me exaltaba.

-iComo tú, río Pachachaca! - decía a solas. (1983:60).

Así, sigue su ejemplo en la forma de desplazarse entre los otros, fortalecido por la energía cósmica transmitida por el río: “iSí! Había que ser como ese río imperturbable y cristalino, como sus aguas vencedoras. iCómo tú, río Pachachaca!" (1983:61).

De esta forma, el río en la obra de Arguedas es fundamental, pues asume formas simbólicas. Este puede estar representado en los animales como el toro, la culebra o el caballo; en los fenómenos culturales como la candela o la música; fenómenos sociales como los movimientos de reivindicación; fenómenos naturales como el rayo y el viento. Todos ellos demuestran una poética de la movilidad, la misma que muestra la tremenda vitalidad del río que vive en cada corazón del hombre.

\section{El río como metáfora del los impulsos sociales}

La figura del río está presente en el movimiento social, puesto que yawar mayu representa los momentos de crisis cósmica o social. Primero en la danza guerrera, y luego la danza y la guerra juntas. Toda esta metáfora del río es traslada a los contextos sociales, "ríos de gente", para señalar el desplazamiento masivo de la personas de un espacio a otro. Tal como se representa en el poema "Tupac Amaru kamaq taytanchisman (haylli-taki)" donde se plantea la reivindicación del indio, quien fue relegado desde el descubrimiento y posterior colonización. El poema rememora ese acontecimiento que remeció la matriz cultural andina; el desencuentro de dos mundos. Desde entonces, el indio y su tierra sufrieron un sistemático proceso de desterritorialización. Proceso que continúa cuando el indio llega a la ciudad donde son ubicados en los desiertos. Esto ocurrió en Lima cuando se produce el proceso de migración intensa en 
los 30 y los $50^{4}$. Ya que en momentos de crisis o hambrunas, los "zorros de arriba" deciden, algunos de ellos, bajar a la costa, realizar un "asalto al centro" a través de un descenso torrentoso que pone en marcha un proceso de reterritorialización para la "reconquista", una "reversión culturizadora"5. Arguedas ha calificado a este movimiento andino como "renovación", "resurrección", "insurgencia" del universo andino en el espectro nacional y le ha otorgado vida intensa designándolo como "cinturón de fuego". Esta expresión está en contra de la nominalización despectiva de "barriada". Este avance sobre la ciudad no implica un abandono del campo o de la comunidad, sino que tiene un mecanismo muy similar al crecimiento de los árboles, mientras más avanzan sobre la ciudad, más se profundizan en sus valores culturales autóctonos. Por ello, en el poema se recurre al mito, a los dioses andinos como el amaru para que fortalezca sus avances y los acompañe con su imaginario. El poema representa a la figura mítica del Amaru', el dios serpiente, como el verdadero Wiraqocha, quien se ha establecido en el ande, espacio geocultural desde donde imparte su magisterio y con cuyas enseñanzas sus hijos deciden enfrentar y vencer a los falsos wiraqochas que viven en Lima. Así se genera una pulsión sociocultural a través del descenso socialmente torrentoso y mítico de la sierra a la costa. Una pulsión que evoca a la figura mítica del Inkarri, o el despertar de los ríos.

Este vínculo entre el hombre y la naturaleza es lo que "enardece" la escritura de Arguedas. Así aparece como "un impulso ineludible" no puede contener la pulsión de su escritura. Lo que provoca el despliegue del poema es el tema de la migrancia, de los desencantos, de los furores y de las tristezas del hombre del ande. Él descubre que el quechua es el idioma capaz de traducir y encausar estos trances del espíritu, puesto que este sistema linguístico contiene el espesor de la palabra capaz de soportar el tránsito de los sentimientos entre el hombre y la naturaleza.

En el poema se puede observar dos momentos del avance indio. El primero lo realizó Túpac Amaru y los españoles; el segundo lo realizan los descendientes de Túpac Amaru, los nuevos indios que avanzan sobre la ciudad: "Desde el

4 Cfr. Matos Mar, José Desborde popular y crisis del estado. Veinte años después. Lima: Fondo Editorial del Congreso del Perú, 2004. P.33-39.

5 Cfr. Bueno, Raúl "Heterogeneidad migrante y crisis del modelo radial de la cultura" en su libro Antonio Cornejo Polar y los avatares de la cultura latinoamericana. Lima: Fondo Editorial de la UNMSM, 2004; p. 64.

6 Cfr. Cornejo Polar, Antonio "Condición migrante e intertextualidad cultural: el caso de Arguedas". En Revista de Crítica Literaria Latinoamericana, Año 21, N. ${ }^{\circ} 42$, Lima- Berkeley, 2do semestre de 1995; p. 107.

7 La idea del impulso ineludible, de la imposibilidad de dejar de escribir, de corregir la escritura de los otros tiene que ver con la responsabilidad como escritor, pues se constituye en un acto ético que contiene respuesta y responsabilidad. 
tiempo en que luchaste con el acerado y sanguinario español, desde el instante en que le escupiste a la cara; desde cuando tu hirviente sangre se derramó sobre la hirviente tierra, en mi corazón se apagó la paz y la resignación. No hay sino fuego, no hay sino odio de serpiente contra los demonios, nuestros amos" (11). Desde entonces, todo empezó a hervir: la sangre de Túpac Amaru, la tierra, el corazón de los hijos. Estos enfrentamientos y avances se explican con las categorías andinas del huaico o lloqlla, los cuales desarrollan un movimiento devastador.

El poema representa el desplazamiento vertiginoso que viene desde la sierra hasta la costa. Este movimiento está graficado de distintas formas. Por ejemplo, los famosos zorros, recordados en Dios y hombre de Huarochirí, se distinguen como el zorro de abajo, el zorro de la costa, el criollo, el blanco; y el zorro de arriba, el hombre andino. El desplazamiento del zorro cuando baja de las cubres es similar al del Amaru: zigzagueante. Aparece y desaparece, va de un lado al otro. Otro elemento configurativo es el camino que realiza el hombre para bajar una montaña, no es recto, sino zigzagueante como una serpiente, un inmenso Amaru extendido. Es el mismo movimiento de los ríos que bajan hacia el mar, hacia la costa cuando se abren paso en medio de las quebradas o "cortando el mundo". El huayco o la lloqlla avanza poderosamente destruyendo todo, esta fuerza es traslada a una lloqlla social, pues tiene el mismo mecanismo; aunque a veces el huayco traza un camino más recto por lo desatado de su fuerza.

Hay una imagen de similitud en el desplazamiento entre el agua y el viento y el fuego. Este movimiento es observado por Arguedas para calificar el desplazamiento de los hombres hacia la costa, y de la costa hacia el centro de Lima "Cuando el ischu de las cumbres se quema, el fuego avanza como el viento, como el agua; las llamas no son altas pero corren, lamiendo, bajan las gargantas, vuelven a subir a las lomadas; van como volando a ras del suelo, lenguas de lenguas, sin descanso" (1987: 30). Entonces, los hombres bajan a la costa como un inmenso cuerpo social, como un inmenso Amaru, como un río en repunte, como candela en movimiento. Este es el camino recorrido por el sujeto migrante que deja su espacio en busca de "sangre" que le permita continuar con su vida, tal como lo hace Demetrio Rendón Willka, personaje de la novela Todas las sangres.

Willima Rowe, refiriéndose a la degradación de una economía y que es representada en El zorro de arriba y el zorro de abajo, menciona dos procesos naturales aplicables a este fenómeno: el huayco-lloqlla y el yawar mayu:

Entre los cambios históricos resulta de la coincidencia de dos procesos que se relacionan entre sí pero que aquí trataremos separadamente. El primero tiene que ver con la ruptura de las barreras sociales y cultura- 
les, permitiendo así posibilidades de transformación mutua previamente obstaculizadas. Entre los símbolos que encarnan la ruptura de barreras, hay dos que sobresalen: el yawar mayu y el huayco. Símbolo poderoso en toda la obra de Arguedas, el yawar mayu incluye entre sus múltiples significados el de una fuerza que se desborda y carga con ella los elementos desarraigados, fuerza trágica pero también con signo de renovación" ${ }^{8}$.

A esta fuerza trágica y de renovación, Matos Mar la ha denominado "el desborde popular". La idea del desborde en el campo está asociada a las crecidas de los ríos, cuando estos rompen sus límites revientan sus cauces e inauguran otros, o en palabras de Arguedas, cuando describe las lloqllas que bajan de las alturas como ríos: "Se han hecho moldes y todos han reventado. ¿Quién carajo mete en un molde a una lloqlla?" ¿Ud sabe lo que es una lloqlla. - La avalancha de agua, de tierra, raíces de árboles, perros muertos, de piedras que bajan bateando debajo de la corriente cuando los ríos se cargan con las primeras lluvias en estas bestias montaña" (Arguedas 1996: 87).

Es esta lloqlla social la que baja de los andes como un río de gente. Con su poder devastador cerca la ciudad. Absorben la vida de la naturaleza que está graficada como un "huiaco": "iEstamos vivos; todavía somos! Del movimiento de los ríos y de las piedras, de la danza de los árboles y montañas, de su movimiento, bebemos sangre poderosa, cada vez más fuerte". Con esta vitalidad, llega a Lima: "Al inmenso pueblo de los señores hemos llegado y lo estamos removiendo. Con nuestro corazón lo alcanzamos, lo penetramos; con nuestro regocijo no extinguido, con la relampagueante alegría del hombre sufriente que tiene el poder de todos los cielos, con nuestros himnos antiguos y nuevos, lo estamos envolviendo". (Arguedas, 1984:17). El pueblo indio muestra su plasticidad cultural, la de incursionar en nuevos espacios adecuándose a los contextos. Este avance indígena sobre las ciudades es observado en el desempeño protagónico del indio, como sustancia y como productor; lo cual resulta notorio en nuestro tiempo. Además, se ha ampliado a todos los discurso modernos o postmodernos, experimentando una "emergencia indígena en Latinoamérica” (Bengoa 2000: 11). José Antonio Mazzotti escribe que: "Publicados principalmente en revistas durante la década del 60, los poemas de Arguedas anunciaba una movilización social cuyas arista culturales pueden oírse treinta años más tarde en los clubes departamentales de la capital y en fenómenos como la 'Chicha' y la 'tecno-cumbia'. Que han definitivamente reconfigurado, a manera de huaico de castellano andino, el hispanizado y arcaico rostro de la Ciudad de los Reyes".

8 Rowe, William. "Deseo, escritura y fuerzas productivas". En: Arguedas, José María. El zorro de arriba y el zorro de abajo. Edición crítica de Eve-Marie Fell. Madrid: ALLCA XX, 1996a; p. 336.

9 Mazzotti, José Antonio. Ob. cit., p. 47. 
Vinculando el fuego puro, el amor y el odio, encuentra Gustavo Gutiérrez que: "De allí nace la fuerza y la esperanza que llevarán a un pueblo a hacer lo que Túpac Amaru no pudo; bajar desde las tierras que les fueron arrebatadas, hacia Lima" 10 , para luego cercar esta ciudad que los maltrata. Esto "sin odios que ensucien el ser humano, con amor de calandria, de paloma encantada" 11 . Esto permitirá la construcción de un mundo nuevo que contenga "la fuerza y los valores sociales del mundo indígena”; tal como lo advierte Antonio Cornejo Polar, quien encuentra que en este poema se plasma poéticamente la gran utopía andina y que esta utopía es producto de la fe porque el poema: "Es la plasmación más intensa del proceso de fundación de esa nueva realidad y de la índole profunda del mundo que se avecina con vigor indetenible" (Cornejo Polar 1996: 298). Esta es la gran utopía que se concretaría cuando el avance de los hombres andinos sitie a la ciudad de mil cabezas o se establezca un diálogo. Así se pueda unir lo diverso; tal vez no en armonía, pero sí en comprensión y tolerancia. Mazzotti, leyendo este poema y confrontando lo mencionado por Arguedas, quien sostenía que el indígena estaba bendecido por la naturaleza, que albergaba odio y amor en su pecho y que cuando estos se desencadenaban lo hacía con toda su materia incluyendo a su lenguaje, encuentra que esto también se manifiesta en la forma en que está escrito el poema:

El poema de Arguedas reproduce ese movimiento vertical y horizontal, reactualizando la 'materia viva' a través de expresiones exclamativas, meditativas, descriptivas, proféticas y performativas que nos recuerdan, por su vigor y fuerza, un verdadero 'huaico' verbal [...] Como se ve, tal 'deslizamiento' de la naturaleza, simbolizado por el aluvión verbal que materializa esta poesía, constituye una irrupción en la institucionalidad de las letras peruanas ${ }^{12}$.

Entonces, se puede establecer que en la poesía de Arguedas hay un vínculo entre el hombre y la naturaleza, entre la pachamama y uno de sus hijos: el hombre; los otros hijos son las plantas, los árboles, las raíces, los troncos, los animales. Entre ellos hay un vínculo; pero también el vínculo se establece en su lenguaje, en su lengua el quechua. Por ello, cuando el andino desata sus amores o sus odios, lo hace con toda la materialización de la naturaleza, ya que provienen de una misma raíz, de una misma madre porque su vitalidad ha sido cogida de los ríos, de la piedras, de la sangre poderosa de la naturaleza que también hierve cuando la sangre del hombre está llameante. Es un mismo sentir porque el hombre es su hijo "desde cuando tu hirviente sangre se derramó sobre la ardiente tierra", escribe en el poema Túpac Amaru.

10 Gutiérrez, Gustavo. Entre las calandrias. Un ensayo sobre José María Arguedas. Lima: CEP, 2003; p. 27.

11 Ibídem, pp. 28-29.

12 Mazzotti, José Antonio. Ob. cit., p. 46. 
Esta imagen del movimiento del río lo siente en el baile, esto ocurre cuando asiste a una fiesta patronal que provoca la escritura del poema "Katatay": "Escribí este himno luego de haber visto bailar a mis hermanos". Arguedas proyecta cómo será este país nuevo y recuerda lo que ha sucedido en otros contextos donde los hombres sufrientes han logrado concretizar su proyecto liberador. El poeta sacerdote muestra a la naturaleza y al hombre vivos, en movimiento; luego lanza la invocación, la búsqueda del Dios serpiente, del Amaru, a quien insistentemente le informa que están vivos, que no han muerto con su muerte, ellos están para continuar el proyecto liberador que el dios Amaru emprendió: "Llegaremos más lejos de cuanto tú quisiste y soñaste. / Odiaremos más que cuanto tú odiaste; / amaremos más de lo que tú amaste, con amor de paloma encantada, de calandria. / Tranquilo espera, con ese odio y con ese amor sin sosiego y sin límites, lo que tú no pudiste lo haremos nosotros". Por ello, es que proyectan un mundo donde los hombres sufrientes ahora son libres: "Me cuentan que en otros pueblos / los hombres azotados, los que sufrían / son ahora águilas, cóndores de inmenso vuelo"; pero para que ello suceda primero tienen que recobrar su tierra: "[...] hemos de lanzarnos, hasta que nuestra tierra sea de veras nuestra tierra y nuestro pueblos nuestro pueblos". Solo recobrando su tierra, tendrán la libertad de las águilas y cóndores. En estos años, se produce la reforma agraria que fue una forma de retornar la tierra a sus dueños; así, siguiendo el lema de "la tierra es de quien la trabaja", se devolvió algo de la tierra a los campesinos.

Considerando esta avalancha migratoria andina, la pregunta es dónde están los andinos. La respuesta es contundente en el poema. Están en todos los lados, están en las alturas, en la parte más alta de la punas, como también en las pampas más próximas al mar: "Hay quienes se aferran a sus tierras amenazadas y pequeñas. Ellos se han quedado arriba, en sus querencias y, como nosotros, tiemblan de ira, piensan, contemplan". Mientras que los otros, los que bajaron a la costa: "Escucha, padre mío: desde las quebradas lejanas, desde las pampas frías o quemantes que los falsos wiraqochas nos quitaron, hemos huido y nos hemos extendido por las cuatro regiones del mundo". Están esparcidos por todo el Tahuantinsuyo. Si están en las cuatro regiones, espacial y simbólicamente, están recuperando las tierras del imperio, lo están completando como un inkarri sociocultural. Así como fue despedazado el Inkarri y luego se junta; así sus hijos juntan las tierras trozadas del Tahuantinsuyo hasta hacerlos retornar: "Somos miles de millares, aquí, ahora. Estamos juntos; nos hemos congregado pueblo por pueblo, nombre por nombre". Una lectura mítica de este desplazamiento de los dioses de la sierra hacia la costa se presenta cuando se explica que, por ejemplo, Wiracocha se desplaza desde las regiones altipláni- 
cas recorriendo las quebradas hasta llegar a la $\operatorname{costa}^{13}$. Tal como se explica en el poema, ahora el padre Túpac Amaru es desplazado por los migrantes andinos desde la sierra hacia la costa, como ocurre con ellos mismos.

A pesar de los múltiples intentos por borrar esta cultura andina, Arguedas encuentra una palabra contundente en el quechua chanca que expresa la tremenda vitalidad del ser indio: Kachkaniraqmi, "a pesar de todo aún es", "existe todavía con todas las posibilidades de su reintegración y crecimiento". A pesar de las oleadas sucesivas extirpadoras siguen juntos contemplando el pachawaray, el amanecer del mundo; amaneciendo en días, en años, en siglos. Este triunfo del pueblo indio, Arguedas lo observa con mayor nitidez en el canto, donde los invasores han tenido que asumir el canto indio; realidad que no se ha dado en otros países como México, Argentina y Chile, donde han tenido que aprender el canto de los invasores ${ }^{14}$.

También es pertinente la noción de kawsay que propone Larrú: "Uno de ellos es la noción de naturaleza viviente que solemos denominar kawsay y que nos demuestra cómo es que no existe una separación entre el sujeto humano y los elementos de la naturaleza, más bien existe una suerte de interacción comunitaria". Arguedas, cuando explica el universo de los niños indios, nos presenta esta naturaleza viviente:

Así como las montañas y los ríos tienen poder sobre los seres vivos y ellos mismos son seres vivos, todo lo que hay en el mundo está animado a la manera del ser humano. Nada es inerte. Las piedras tienen "encanto", lloran si no pueden desplazarse por las noches, están vinculadas por odios o amores con los insectos que habitan sobre ellas o debajo de ellas o que, simplemente, se posan sobre su superficie. Los árboles o arbustos ríen o se quejan; sufren cuando se les rompe una rama o se les arranca una flor; pero goza si un picaflor baila sobre una corola. Algunos picaflores pueden volar hasta el sol y volverse. Los peces juegan en los remansos. Y todas estas cosas vivas están relacionadas entre sí. Las montañas tienen ciertas zonas especialmente sensibles sobre las cuales el hombre puede reposar pero no quedarse dormido, a riesgo de que las montañas le transmitan alguna dolencia que puede ser mortal ${ }^{15}$.

Arguedas, en el poema, muestra que no solamente se sitia la ciudad de Lima, sino todas las ciudades del interior que ejercían poder sobre las comunidades; por ello, habla de "esta masa casi amorfa que corre cual un tumultuoso e incontenible río andino desconocido". Arguedas llama a estos pueblos que

13 Rostworoski, María. Estructuras andinas de poder. Ideología religiosa y política. Lima: IEP, 2007; p. 34. 14 Cfr. Arguedas, José María. Ob. cit., 1942, pp. 18-19.

15 Arguedas, José María. "Algunas observaciones sobre el niño indio actual y los factores que modelan su conducta”. En: Qepa Wiñaq... Siempre. Literatura y antropología. Edición crítica de Dora Sales. Madrid: Iberoamericana, 2009, p. 173. 
circunda la ciudad "cinturones", porque están apretando a la ciudad, para ingresar a su semiosfera. Allí hay fuego que impulsa; es la renovación que viene de lo profundo, que no es percibida por el ojo citadino acostumbrado solo a lo superficial. Arguedas hace un llamado a un ojo más profundo para percibir estas profundidades. Él encuentra estas lógicas de movimiento cuando comenta el avance de las formas musicales que "han penetrado y siguen penetrando muy dentro de las ciudades hacia las capas sociales más altas" ${ }^{16}$. En conclusión, este poema nos representa al Amaru social que observa Arguedas en los $60 \mathrm{y}$ que ahora, en este tiempo, continúa en su avance vertiginoso, cholificando, indianizando la ciudad de los reyes ${ }^{17}$.

En el poema Katatay, está presente la figura del río pero en forma de un amaru. Temblar es el animismo que está en todo universo, el ánimo, el movimiento vibrátil. En este canto, no hay un temblor de miedo; sino el ánimo y la vida que intensifican la esperanza y la voluntad. En Arguedas, el temblar es el latido, el movimiento de los ríos que hace temblar a la tierra a su paso; es la danza sobre la tierra, que hace entrar en danza a la tierra misma, porque si tiembla entonces está vivo. Esta idea del movimiento en Arguedas está siempre asociada la vida del hombre con los movimientos de la naturaleza, la misma que es expresada en sus canciones. Así, según William Rowe: "El ensayo 'El carnaval de Tambobamba' relaciona el yawar mayu con el movimiento de los grades río andinos hacia la selva, movimiento que domina al final de Los ríos profundos" (Rowe 1996: 336). Este movimiento tembloroso de la tierra es lo que se trasmite a los hombres, al inmenso cuerpo social; así como el río o la lloqlla ingresa como un inmenso torrente que no se detiene, que avanza, de igual forma ocurre con la gran masa social cuando avanza en busca de su reivindicación. Estos movimientos traen como consecuencia drásticas transformaciones, como por ejemplo una revolución social. Existen cantos y danzas guerreras como el Wiphala que reproducen los enfrentamientos. Esto nos lleva a afirmar que la danza y la música son los impulsores de las acciones. Ello lo podemos ver en varias danzas que reproducen o simulan en su interpretación los enfrentamientos entre bandos. Otro elemento del poema es la sombra que es vista como un ánimo, como una fuerza, es una parte íntima del ser individual y social; así, el hombre es intenso y fuerte cuando la sombra está viva porque él la alimenta y es el signo de su vida. Porque el pueblo se levanta: "Dicen que tiembla la sombra de mi pueblo; / está temblando porque ha tocado la triste sombra del corazón / de las mujeres”. Esta sombra es individual, social y divina; la poseen todos. De allí que es posible leerla como un ánimo o como una fuerza sensible. Una sombra individual esta

16 Ibídem, p. 25.

17 Un estudio que muestra este avance en Lima es el realizado por Rolando Arelllano C. y David Burgos A. titulado Ciudad de los Reyes, de los Chávez, los Quispe. Lima: Epensa, 2004. 
en los hombres, en las mujeres, en las plantas, en los animales. Un ejemplo de esta sombra colectiva se presenta cuando se unen todos los hombres del pueblo y forman una sola sombra, una fuerza, un ánimo poderoso como la revolución. Por ello, es que la sombra tiene la forma de un resplandor, de una luz poderosa. No es una sombra oscura, un remedo del objeto, sino una fuerza, un ánimo que avanza y atemoriza. Así, en el inicio del poema temen la sombra poderosa que viene de las divinidades más altas en forma de luz, como la sombra luminosa del sol. De igual magnitud y más poderosa aún es la sombra que construirán los hombres cuando se junten, cuando formen un solo gran pueblo que genere resonancias revolucionarias; tal como se grafica en la última parte del poema: "Levántate, ponte de pie; recibe ese ojos sin límites! / Tiembla con su luz; / sacúdete con los árboles de la gran selva, / empieza a gritar". Esta es la invocación al levantamiento que formula el hablante lírico. El levantamiento social se presenta cuando se forma una sola gran sombra: "Formen una sola sombra, hombres, hombres de mi pueblo; / todos juntos / tiemblen con las luz llega. / Beban la sangre áurea de la serpiente de dios". La sustancia poderosa de la serpiente es su sangre hirviente. Estas dos sustancias (luz y sangre) están marcadas por la intensidad y permiten orientar y nutrir el movimiento de los hombres andinos porque el poema está hablando del pueblo indio: "La sangre ardiente llega al ojo de los cóndores, / carga los cielos, los hace danzar, / desatarse y parir, crear. / Crea tú, padre mío, vida; / hombre, semejante, mío, querido”. Esta es la sangre que engendra. Aquí se desarrolla una figura sumamente compleja: la tierra que fecunda a los seres del hanan. Ahora esta sangre engendradora, hirviente, sangre en movimiento llega a los ojos de los cóndores, lo que desata un movimiento en el cielo desencadenando la creación y la vida. Así como hay un movimiento en la tierra de tal dimensión que llega a replicar en el cielo, donde se encuentra el creador, quien es capaz de parir y crear; un rayo de sangre, de fuego, que haciende de la tierra al cielo. "Dicen que en los cerros lejanos / que en los bosques sin fin, una hambrienta serpiente, / serpiente diosa, hijo del Sol, dorada, está buscado hombres". Esta serpiente es el Amaru que convoca a los hombres para su levantamiento; no para tragarlos, sino para darles su sangre luminosa, áurea, para que formen una sola gran sombra. El amaru es vinculado a los movimientos de reivindicación, como el caso de Túpac Amaru y el retorno mesiánico del Inkarry, que fue despedazado y ahora se junta para completarse. De igual forma, la serpiente hambrienta de justicia busca a los hombres en las estancias y en los bosques (recuérdese los movimientos del gran pajonal, los movimientos de los indígenas) para formar todos juntos un pueblo en movimiento. Se busca la unión entre el movimiento de la naturaleza, el baile, el temblor de la tierra, el temblor del hombre, el temblor del pueblo; todo ello connota vida, esto da cuenta de que están en kawsay, están en vida, están en movimiento como los ríos. 
Finalmente, los ríos de sangre o las piedras de sangre hirviendo dan cuenta de esta poética del movimiento, esto se observa en la potencia que encierra la piedra. Esta contiene movimiento, tensión y crisis. Arguedas en Los ríos profundos explica:

Me acordé, entonces, de las canciones quechuas que repiten una frase patética constante: "yawar mayu", río de sangre; "yawar unu", agua sangrienta; "Puk'tik' yawar k'ocha”, lago de sangre que hierve; "yawar wek'e", lágrima de sangre. ¿Acaso no podría decirse "yawar rumi”, piedra de sangre, o "puk'tik yawar rumi", piedra de sangre hirviente? Era estático el muro, pero hervía por todas sus líneas y la superficie era cambiante, como la de los ríos en verano, que tienen una cima así, hacia el centro del caudal, que es la zona temible, la más poderosa (1983:14).

Esta es la escritura-río de Arguedas, escritura que "golpea en la conciencia del lector". Escritura serpenteante, vibrátil que muestra la tremenda vitalidad de la cultura andina, siempre en movimiento. Crea toda una poética del movimiento. Una energía cósmica encarnada en el río que, con todo su poder, llega a todos los espacios.

\section{Referencias bibliográficas}

ARELLANO C., Rolando y David BURGOS A. (2004). Ciudad de los Reyes, de los Chávez, los Quise. Lima: Epensa.

ARGUEDAS, José María (1942).“La aurora de la canción popular mestiza. La victoria de lo indio". En: Revista Yachaywasi. Lima: N. ${ }^{\circ} 14$, año 3, junio; pp. 18-19.

(1944) "Un método para el caso linguíístico del indio peruano". En: Historia. Lima: Vol. 2, N. ${ }^{\circ}$, enero-junio, p. 32.

(1984) Katatay. Lima: Horizonte.

(1983) Todas las sangres. Lima: Horizonte.

(1983) Los ríos profundos. Lima: Horizonte.

(1986) [Testimonio e intervención]. En: Primer Encuentro de Narradores Peruanos. Lima: Latinoamericana Editores.

(1987) Indios, mestizos y señores. Lima: Horizonte.

(1989) Canto Kechwa. Lima: Horizonte.

(2009) "Algunas observaciones sobre el niño indio actual y los factores que modelan su conducta". En: Qepa Wiñaq... Siempre. Literatura y antropología. Edición crítica de Dora Sales. Madrid: Iberoamericana.

BENGOA, José (2000).La emergencia indígena en América Latina. Santiago: Fondo de Cultura Económica.

BUENO, Raúl (2004). Antonio Cornejo Polar y los avatares de la cultura latinoamericana. Lima: Fondo Editorial de la UNMSM.

CORNEJO POLAR, Antonio (1976). "Arguedas, poeta indígena”. En: Larco, Juan. Recopilación de textos sobre José María Arguedas. La Habana: Casa de las Américas; pp. 169-176. 
(1995) “Condición migrante e intertextualidad cultural: el caso de Arguedas”. En Revista de Crítica Literaria Latinoamericana, 42; pp. 101-109.

(1996) “Un ensayo sobre ‘Los zorros’ de Arguedas”. En: Arguedas, José María. El zorro de arriba y el zorro de abajo. Edición crítica de Eve-Marie Fell. Madrid: ALLCA XX; pp. 296-306.

CHURATA, Gamaliel (1957). El Pez de oro. La Paz: Edit. Canata.

GONZALES, María (2011). Oposiciones y complementariedad en Diamantes y pedernales. Tesis: UNMSM.

GUTIÉRREZ, Gustavo (2003). Entre las calandrias. Un ensayo sobre José María Arguedas. Lima: CEP.

HUAMÁN, Miguel Ángel (1988).Poesía y utopía andina. Lima: DESCO.

LANDEO, Pablo (2010). Categorías andinas para una aproximación al Willakuy Umallanchikpi kaqkuna (seres imaginarios del mundo andino). Tesis. Lima: UNMSM.

LARRÚ SALAZAR, Manuel (2003). “La utopía posible en la poesía de Arguedas”. En: Lhymen 2, pp. 63-71.

(2010) "De una visión indigenista a una visión andina en la obra de José María Arguedas”. En Con textos. Revista Crítica de Literatura 1; pp. 11-28.

LIENHARD, Martín (1992). La voz y su huella. Lima: Horizonte.

(1996) “La ‘andinización’ del vanguardismo urbano”. En: Arguedas, José María. El zorro de arriba y el zorro de abajo. Edición crítica de Eve-Marie Fell. Madrid: ALLCA XX; pp. 321-332.

MAMANI Macedo, Mauro (2011). José María Argueda. Urpi, fieru, quri, sonqoyky. Estudio de la poesía de Arguedas. Lima: PETROPERU.

MAMANI Macedo, Porfirio (2007). La sociedad peruana en la obra de José María Arguedas. El zorro de arriba y el zorro de abajo. Lima: Fondo editorial de la Facultad de Letras de la Universidad Nacional Mayor de San Marcos.

MATOS MAR, José (2004). Desborde popular y crisis del estado. Veinte años después. Lima: Fondo Editorial del Congreso del Perú.

MAZZOTTI, José Antonio (2002). Poéticas del flujo. Migración y violencia verbales en el Perú de los 80. Lima: Fondo Editorial del Congreso del Perú.

PINILLA, Carmen María (Editora) (2004). José María Arguedas. iKachkaniraqmi! iSigo siendo! Textos esenciales. Lima: Fondo editorial del Congreso del Perú.

RAMA, Ángel (1982). Transculturación narrativa en América Latina. México: Siglo XXI.

REBAZA SORALUZ, Luis (2000). La construcción de un artista peruano contemporáneo. Lima: PUCP.

ROSTWOROSKI, María (2007). Estructuras andinas del poder. Ideología religiosa y política. Lima: IEP.

ROWE, William (1991).“La complejidad semántica de la poesía de Arguedas”. En: Pérez, Hildebrando y Garayar, Carlos. José María Arguedas. Vida y obra. Lima: Amaru, pp. 216-205.

(1996) “Deseo, escritura y fuerzas productivas”. En: Arguedas, José María. El zorro de arriba y el zorro de abajo. Edición crítica de Eve-Marie Fell. Madrid: ALLCA XX, pp. 333-340.

(1996) Ensayo arguedianos. Lima: Universidad Nacional Mayor de San Marcos/SUR Casa de Estudios del Socialismo. 
SALES, Dora (2009). Qepa Wiñaq... Siempre. Literatura y antropología. Madrid: Iberoamericana.

TAUZIN, Isabelle (2007). El otro curso del tiempo. Una interpretación de Los ríos profundos. Lima: IFEA/Lluvia editores.

USANDIZAGA, Helena (2006). "Amauru, wiku, layk'a, supaya o demonio: las fuerzas del mundo de abajo en Los ríos profundos". En R. Franco, Sergio (editor). José María Arguedas: hacia una poética migrante. Pittsburgh, Universidad de Pisttsburgh; pp. 227-246. 